\title{
Validation of A CFD Fire Model Using Two Step Combustion Chemistry Using the NIST Reduced-Scale Ventilation-Limited Compartment Data
}

\author{
JASON FLOYD ${ }^{1}$ and KEVIN MCGRATTAN ${ }^{2}$ \\ ${ }^{1}$ Hughes Associates, Inc. \\ 3610 Commerce Dr., \#817 \\ Baltimore, MD 21227 \\ ${ }^{2}$ Building and Fire Research Laboratory \\ National Institute of Standards and Technology \\ Gaithersburg, MD
}

\begin{abstract}
Recent testing by the Building and Fire Research Laboratory of the National Institute of Standards and Technology collected a large dataset of species, temperature, velocities, and heat fluxes for a wide range of fuels burning at varying degrees of ventilation inside a reduced scale enclosure. This dataset is extremely well documented with uncertainties well characterized, making it an excellent choice for fire model validation. Selected data from a subset of tests was used as part of a validation exercise using FDS v5. FDS v5 contains a new method of decomposing the mixture fraction coupled with a new combustion model that allows it to predict (rather than assume) CO formation in under-ventilated fires. Eleven tests were simulated and predicted vs. measured data comparisons were made for seven physical quantities distributed over twelve measurement locations. Results show the new combustion model is able to reproduce test conditions over a range of fuels and fire sizes.
\end{abstract}

KEYWORDS: CFD, validation, compartment fires, modeling

\section{INTRODUCTION}

\section{Desired Fire Model Traits}

To be broadly applicable, a computational fluid dynamics (CFD) model for fire simulation requires a number of major elements: the ability to transport multiple species of interest, a model for combustion (reactions that change one set of species to another with the release of energy, a model for radiation transport, a solid phase model for computing heat transfer into materials and the energy and mass inputs resulting from a decomposing material, and some manner of handling droplets from sprinklers/water mist systems including transport, evaporation, and solid phase interactions. Additionally, one would desire that the model do all those items well (model predictions match experiments within experimental uncertainty), be able to handle a wide range of length scales (Bunsen burner to forest fire), fuels, and materials, and be usable by a typical fire protection engineer (model complexity and computational hardware/time requirements).

The current state of fire CFD models is that any model (given an adequate grid) will do well in terms of transporting gasses and performing heat transfer into simple (i.e. non-decomposing) surfaces. This is done with varying degrees of input complexity and computational resource requirements. There are a number of approaches for radiation transport that have been used including Monte-Carlo methods, $\mathrm{P}_{\mathrm{n}}$ methods, and various flavor of discrete ordinates methods. Each of these has its advantages and disadvantages, but generally most CFD fire models make use of some form of a discrete ordinates method. While one could argue that aspects of radiation transport, efficient generation of absorption coefficients and computing source terms on large grids, could use more development, the actual mechanics of solving for a radiative flux given those inputs is well established. That leaves combustion, decomposing solid phase, and droplets.

Transport and evaporation of droplets is key for evaluating water mist systems or simulating fuel spray fires. A key input is of course the radiant flux which serves as a mechanism for evaporating droplets as is the interaction of any diluent gasses (water vapor) with the combustion process. Ultimately, however, much of modeling droplets becomes striking a balance between the fidelity of the physics and the resources required. 
Simulating a decomposing solid phase (wood for example) is of great interest to many people; however, while progress is being made in algorithms, the ultimate success will hinge upon how well the fire-fuel feedback can be modeled. This requires in part that one make adequate predictions of the key radiating species, i.e. the combustion model must be robust.

In addition to the needs of the solid phase models, a robust combustion model is desired since gasses such as $\mathrm{CO}$ are of key interest to fire protection engineers, but the ability to predict them in large scale fires has been limited. Also, there is the need to predict extinction in poorly ventilated fires to evaluate risks for backdraft type events. Recognizing that improvements to the previously simple combustion model in FDS could result in across the board improvements in overall capability, a new method of tracking species and computing combustion was implemented in FDS. The remainder of this paper briefly documents the new method and a few key aspects of FDS and then validates the new version using test data from the NIST reduced scale enclosure.

\section{Model Verification and Validation}

The spectrum of model users, those who run the models to those who must approve fire protection designs based on the model runs, are always interested in how good is a model. The process of demonstrating the goodness of a model is Verification and Validation. While definitions of those differ, in general verification shows that the model was developed properly and validation shows that the model can be used for a particular application. For fire modeling, the latter typically means comparing model predictions to fire experiments. How though does one determine the model is performing adequately?

The model will never match an experiment exactly, so how much difference should be tolerated? A recent validation effort undertaken by the US Nuclear Regulatory Commission [1] has suggested that the best one can do is demonstrate that the model predictions and the measured data overlap when uncertainty is accounted for. This uncertainty includes both the measurement uncertainty associated with individual measurements but also model input uncertainties (material properties, heat release rates, dimensions, etc). This is an appropriate metric, though one that is hard to do in practice. For high fidelity models, the less one knows about what the test was, the less certain one will be of the model results. Similarly, the less certain one is of the measured data, the larger the model prediction error can be without being able to say it is incorrect.

Recent validation efforts have attempted to assess FDS's ability to model post-flashover compartments. One recent validation effort compared FDS v4 predictions of temperature with measurements made during a test series at Cardington [2]. The fires consisted of multiple wood cribs in a compartment with an effort to measure the mass loss rate of a small fraction of the wood cribs. FDS predictions of point temperatures were compared with measured data with the conclusion that FDS is unable to predict temperatures in postflashover compartments. However, this study omitted some key aspects of the test and ignored their impact on the model uncertainty. Some key failings were: the mass loss rate data was applied as a time dependent uniform fire source rather than the spatially dependent source that existed, the fuel source was defined using a single heat of combustion (with unknown certainty) that did not make any account for the how the fuel thermal properties change over time, no assessment of the impact of uncertainties in defining the construction materials, and no assessment of the measurement uncertainty. The report ended by observing FDS predictions of average gas temperatures were low by 7 to $30 \%$ without noting what performance could be expected given the test uncertainties.

The model validation shown in this paper, attempts to address the key components of the test uncertainty both in terms of the measured data itself and the impact the test uncertainty has on inputs and the resulting model outputs.

\section{FIRE MODEL (FDS VERSION 5)}

Fire Dynamics Simulator (FDS) version 5 was released in October 2007. A large number of changes were made to FDS from version 4. Key changes are a new method of decomposing the mixture fraction combined with a new two-step combustion model [3], a general scheme for modeling multi-layer, multicomponent reacting surfaces, a reorganization of the source code to enable easier multi-party development and code branching, the implementation of modern software QA concepts using online version control via Google Code $^{\mathrm{TM}}$ open source project hosting, and online user support using Google Group ${ }^{\mathrm{TM}}$ discussion 
forum services. A brief overview of the mixture fraction decomposition and combustion model are provide below.

\section{Multiple Parameter Mixture Fraction}

The single parameter mixture fraction for tracking species that was used in FDS v2 - v4 has been extended into a multiple parameter mixture fraction. The use of multiple parameters allows FDS to account for extinction (two parameter approach) and CO formation and destruction (three parameter approach). The work in this paper was performed using the three parameter mixture fraction. The three mixture fraction parameters, each a conserved scalar, are

$$
Z_{1}=\frac{Y_{\mathrm{F}}}{Y_{\mathrm{F}}^{I}}, Z_{2}=\frac{M_{\mathrm{F}}}{M_{\mathrm{CO}}\left(x-\left(1-X_{\mathrm{H}}\right) \nu_{\mathrm{S}}\right)} \frac{Y_{\mathrm{CO}}}{Y_{\mathrm{F}}^{I}}, Z_{3}=\frac{M_{\mathrm{F}}}{M_{\mathrm{CO} 2}\left(x-\left(1-X_{\mathrm{H}}\right) v_{\mathrm{S}}\right)} \frac{Y_{\mathrm{CO}_{2}}}{Y_{\mathrm{F}}^{I}}
$$

In Eq. 2 and Eq. $3 M_{\mathrm{i}}$ is the molecular weight of species $\mathrm{i}, Y_{\mathrm{i}}$ is the mass fraction of species $\mathrm{i}$, the variable $\mathrm{x}$ represents number of moles of carbon in the fuel, $Y_{\mathrm{F}}^{I}$ is the fuel mass fraction at the fuel source (i.e. dilution of the fuel stream with an inert gas is allowed), $X_{\mathrm{H}}$ is the hydrogen atom fraction in the soot, and $v_{\mathrm{S}}$ is the fixed soot yield. $Z_{1}$ represents the mass fraction of gas that is associated with unburned fuel, $Z_{2}$ represents the mass fraction of gas that is associated with fuel that has oxidized to $\mathrm{CO}$, and $Z_{3}$ represents the mass fraction of gas that is associated with fuel that has oxidized to $\mathrm{CO}_{2}$. Full details on this new approach for tracking species can be found in [3] and [4]. This approach of decomposing $Z$ into components is referred to as creating a mixture fraction vector [5]. The advantage of the mixture fraction is that with the three scalars, a total of seven species are tracked $\left(\mathrm{N}_{2}, \mathrm{O}_{2}\right.$, fuel, $\mathrm{CO}, \mathrm{CO}_{2}, \mathrm{H}_{2} \mathrm{O}$, soot), which reduces both memory requirements and computational time.

\section{Two Step Combustion}

With a single parameter mixture fraction, we can only track one state of a reaction: the fully combusted state that disallows the coexistence of fuel and oxygen. Since neither fuel, nor oxygen can coexist (that would require a second parameter), heat release is computed by taken the gradient of mixture fraction across the stoichiometric surface. Physically this is computing the fuel (or oxygen) mass flux across the flame and assuming it all reacts instantaneously. This works well in general for well ventilated fires; however, it has drawbacks: complete combustion means no computations of extinction or minor product formation, numerical artifacts on coarse grids result in ringing of mixture fraction in regions of high gradients (near the stoichiometric surface) which hinders obtaining the correct heat release rate, and attempting to do flux correction on the ringing also impairs the computation of the correct total heat release rate.

The decomposed mixture fraction means one is no longer is tied to computing gradients. FDS now can track separately fuel and oxygen and the degree to which the combustion reaction has gone to completion. Note that many schemes in the combustion literature involve tracking progress variables (a fractional value of reaction completeness); however, since these variables suffer from the same numerical issues as mass fractions, on coarse grids one can still have difficulties obtaining the correct heat release rate.

Instead, the combustion routine uses directly the species mass fractions as determined by the mixture fraction parameters to determine the heat release rate in two steps: oxidation of fuel to water vapor and $\mathrm{CO}$ and oxidation of $\mathrm{CO}$ to $\mathrm{CO}_{2}$ [6]. In the first step, if a cell contains fuel $\left(\mathrm{Z}_{1}\right)$ and oxygen with the oxygen above a temperature dependent lower limit, the fuel is converted to $\mathrm{CO}$ plus other products $\left(\mathrm{Z}_{1}\right.$ becomes $\left.\mathrm{Z}_{2}\right)$. In the second step if a cell contains $\mathrm{CO}\left(\mathrm{Z}_{2}\right)$ and oxygen and the temperature is high enough to support $\mathrm{CO}$ oxidation, then $\mathrm{CO}$ becomes $\mathrm{CO}_{2}\left(\mathrm{Z}_{2}\right.$ becomes $\left.\mathrm{Z}_{3}\right)$. The full details on this are found in [3] and [4]. It should be noted that this approach does not allow for $\mathrm{CO}$ formation directly from pyrolysis as occurs in oxygenated fuels such as cellulosic materials. 


\section{REDUCED-SCALE EXPERIMENTS}

In 2006, the Building and Fire Research Laboratory undertook a series of 17 fire tests involving a wide range of fuels in a reduced scale enclosure [7]. Seventeen tests involving seven different fuels (including solid, liquid, and gas) were conducted. The tests occurred in a $0.95 \mathrm{~m}$ wide x $1.42 \mathrm{~m}$ deep x $0.98 \mathrm{~m}$ tall compartment with a $0.48 \mathrm{~m}$ wide $\mathrm{x} 0.81 \mathrm{~m}$ tall door centered on one of the $0.95 \mathrm{~m}$ walls. The floor of the compartment was $0.19 \mathrm{~m}$ above the floor of the test facility. The compartment was lined with a ceramic fiber insulating board. The fires were centered on the floor of the compartment. Measurements included temperature, species, velocity, heat flux, and heat release rate. Measurements were processed into 64 channels of data of which 18 channels were selected for use in this paper. The first six tests partially served as shakedowns, and following them, minor changes were made to the measurement apparatus. Data from these tests was not used in this validation effort. Measurement uncertainties were generated for specific time intervals for each measurement point for each test. The reported uncertainties are solely for the measurement process (i.e. the reported uncertainty in temperature does not include a contribution due to the uncertainty in the measured fire size).

This validation study examined 18 measured quantities in 11 tests. These were: 8 gas measurements $\left(\mathrm{O}_{2}\right.$, $\mathrm{CO}_{2}, \mathrm{CO}$, and unburned hydrocarbons made in the front and rear of the compartment above the top of the door), 4 aspirated thermocouples (two locations in the front and rear of the compartment: the upper third and lower third of the compartment), 4 bi-directional probe velocities in the centerline of the doorway, and 2 total heat fluxes on the compartment floor (in front of and behind the burner). During each test, averages of the data were taking over time periods when the heat release rate was quasi-steady state. This process resulted in a total of 36 data points distributed over the 11 tests.

\section{FDS MODEL}

Each of the final eleven tests was modeled with FDS v5.0. A summary of the FDS modeling of the eleven tests is given in Table 1 and Table 2 provides a summary of the fuel inputs used in the FDS modeling. The chemical constituents of the natural gas supply were measured prior to testing.

Table 1. Summary of FDS Simulations of RSE Test Series

\begin{tabular}{|c|c|c|c|c|c|}
\hline $\begin{array}{c}\text { Test } \\
\#\end{array}$ & Fuel & $\begin{array}{l}\text { Burner Type } \\
\text { (dimension) }\end{array}$ & $\begin{array}{c}\text { Max Size } \\
(\mathrm{kW})\end{array}$ & $\begin{array}{l}\text { Time } \\
\text { (s) }\end{array}$ & Fire Specification \\
\hline 6.5 & Natural Gas & $\begin{array}{c}\text { Square burner } \\
(0.13 \mathrm{~m} \text { x } 0.13 \mathrm{~m})\end{array}$ & 425 & 3400 & Measured fuel flow \\
\hline 7 & Heptane & $\begin{array}{c}\text { Pool fire } \\
(0.25 \mathrm{~m} \mathrm{x} 0.25 \mathrm{~m})\end{array}$ & 340 & 5000 & Hood calorimeter \\
\hline 8 & Methanol & $\begin{array}{c}\text { Pool fire } \\
(0.25 \mathrm{~m} \mathrm{x} 0.25 \mathrm{~m})\end{array}$ & 15 & 2645 & Hood calorimeter \\
\hline 9 & Ethanol & $\begin{array}{c}\text { Pool fire } \\
(0.25 \mathrm{~m} \mathrm{x} 0.25 \mathrm{~m}) \\
\end{array}$ & 20 & 3540 & Hood calorimeter \\
\hline 10 & Toulene & $\begin{array}{c}\text { Pool fire } \\
(0.25 \mathrm{~m} \mathrm{x} 0.25 \mathrm{~m})\end{array}$ & 340 & 6150 & Hood calorimeter \\
\hline 11 & Ethanol & $\begin{array}{c}\text { Spray } \\
\text { (into } 0.20 \text { m radius pan) }\end{array}$ & 335 & 4800 & Measured fuel flow \\
\hline 12 & Methanol & $\begin{array}{c}\text { Spray } \\
\text { (into } 0.20 \text { m radius pan) }\end{array}$ & 305 & 3600 & Measured fuel flow \\
\hline 13 & Polystyrene & $\begin{array}{l}\text { Pellet filled pan } \\
(0.11 \text { m radius })\end{array}$ & 15 & 1725 & Hood calorimeter \\
\hline 14 & Polystyrene & $\begin{array}{c}\text { Pellet filled pan } \\
(0.20 \text { m radius })\end{array}$ & 70 & 2340 & Hood calorimeter \\
\hline 15 & Heptane & $\begin{array}{c}\text { Spray } \\
\text { (into } 0.20 \text { m radius pan) }\end{array}$ & 375 & 760 & Measured fuel flow \\
\hline 16 & Polystyrene & $\begin{array}{l}\text { Pellet filled pan } \\
(0.30 \mathrm{~m} \text { radius })\end{array}$ & 360 & 1330 & Hood calorimeter \\
\hline
\end{tabular}


Table 2. Summary of FDS Fuel Definitions (\&REAC Inputs)

\begin{tabular}{|c|c|c|c|}
\hline Fuel & Chemistry & $\begin{array}{c}\Delta \mathrm{H}_{\mathrm{c}} \\
(\mathrm{kJ} / \mathrm{kg})\end{array}$ & $\begin{array}{c}\mathrm{Y}_{\text {Soot }} \\
(\mathrm{kg} / \mathrm{kg})\end{array}$ \\
\hline Natural Gas & $\mathrm{C}_{1.06} \mathrm{H}_{4.08} \mathrm{~N}_{0.016} \mathrm{O}_{0.015}$ & 48249 & 0.015 \\
\hline Heptane & $\mathrm{C}_{7} \mathrm{H}_{16}$ & 44630 & 0.015 \\
\hline Methanol & $\mathrm{CH}_{3} \mathrm{OH}$ & 19935 & 0.000 \\
\hline Ethanol & $\mathrm{CH}_{3} \mathrm{CH}_{2} \mathrm{OH}$ & 28865 & 0.008 \\
\hline Toulene & $\mathrm{C}_{7} \mathrm{H}_{8}$ & 40589 & 0.170 \\
\hline Polystyrene & $\mathrm{C}_{8} \mathrm{H}_{8}$ & 25600 & 0.120 \\
\hline
\end{tabular}

For each test the compartment plus a small region outside the door and above the compartment was modeled. The external region was modeled so that an open pressure boundary condition would not be present at the compartment door. The computational domain was $0.95 \mathrm{~m} \times 2.44 \mathrm{~m} \times 1.50 \mathrm{~m}$ and was gridded with a single computational mesh of $40 \times 100 \times 72(288,000)$ cells. A grid study was performed using test 6.5 with approximately $1 / 2$ and 2 times the number of nodes to establish that the grid was adequate. Figure 1 shows the computational domain. The burner pictured represents the pan for containing the spray fire. The spheres are locations of measurement devices used during the testing.

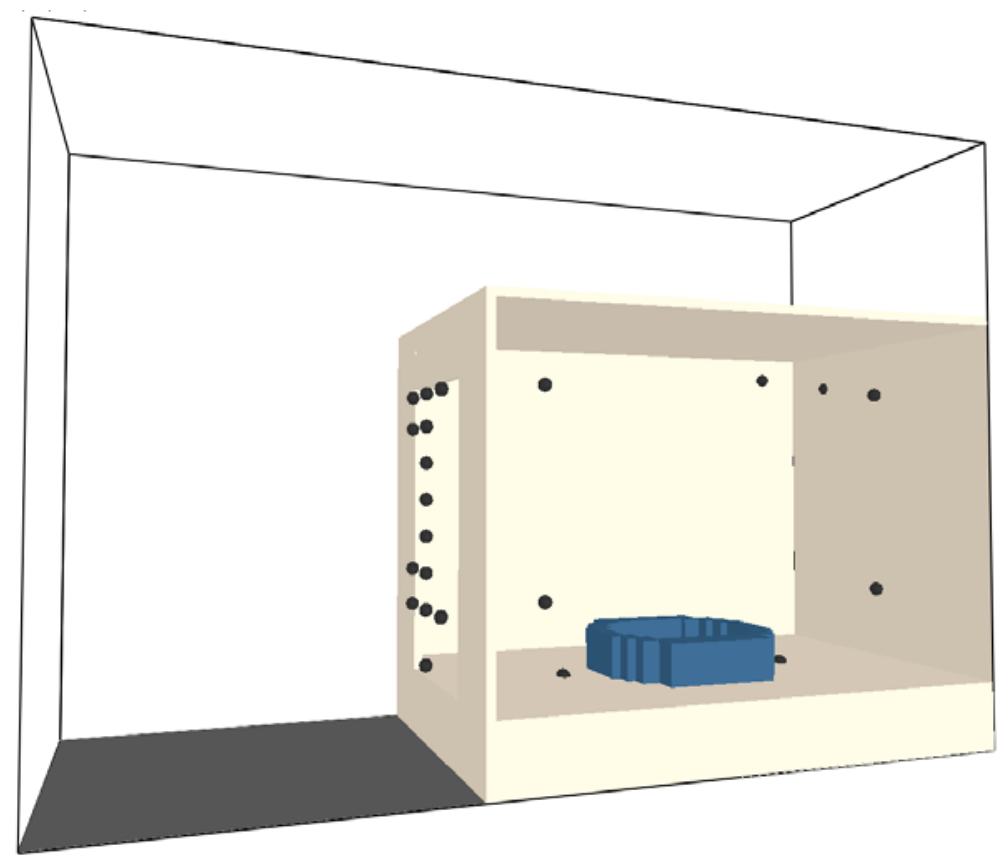

Fig. 1. View of FDS Domain for RSE Simulations

For pool fire tests, the burner was defined with a uniform, time-dependent mass flux of fuel with a temperature equal to the boiling point of the liquid. The gas fire test was similarly set though using a temperature of $100^{\circ} \mathrm{C}$ to represent the slightly preheated fuel leaving the burner. Spay fire tests injected a time dependent flow of droplets assigned fuel appropriate evaporation parameters with a $250 \mu \mathrm{m}$ average diameter through a $90^{\circ}$ cone. The test facility floor was given thermal properties of concrete and the test compartment walls were assigned manufacturer reported properties for the ceramic boards.

In creating the inputs for each simulation, there is some uncertainty to the input data which will impact the FDS predictions being compared with the data. Uncertainties in the fuel flow rate specified in the input file will have an impact on the species production as will uncertainties in the wall thermal properties. Other input data such as fuel type and compartment geometry have little associated uncertainty. Thus, in addition to the eleven RSE tests, the maximum fire size observed in tests \#6.5 (methane with low soot production) and \#7 (heptane with higher soot production) was used to run a series of sensitivity calculations where 
thermal conductivity of the walls was varied by $10 \%$ and where the fire size was varied by the test determined uncertainty. Each calculation was run as quasi-steady state using a large fire and small fire. The change in the predicted quantities was then used to compute FDS uncertainties. These uncertainties were then used when plotting FDS predictions by selecting the closest corresponding uncertainty (i.e. for a large fire with a sooting fuel, the large fire heptane uncertainties were applied to the FDS results). Other uncertainties exist, such as the impact of not including the hood flow and the various flow baffles that existed around the sides of the compartment during the test.

\section{RESULTS}

\section{Sensitivity Calculations}

The sensitivity study results indicated that FDS predictions of the average velocities were not greatly affected by uncertainties in the heat release rate or wall properties with variations of $6 \%$ or less. Similarly upper layer temperature measurements also saw little change with variations of $5 \%$ or less. Lower layer temperatures varied more with changes up to $15 \%$. For the larger fire sizes, heat flux predictions varied by less than $7 \%$, but for the smaller fire sizes the variance was $10 \%$ to $13 \%$. Gas species varied depending upon the fire size. Larger fires saw more variance in oxygen and smaller fires more variance in unburned hydrocarbons. For both this resulted from small absolute changes that were large percentages due to the low levels of either species. $\mathrm{CO}$ and $\mathrm{CO}_{2}$ levels generally varied less than $10 \%$.

\section{Reduced Scale Enclosure Simulations}

Figures 2 through 10 plot the FDS predicted quantities (y-axis) against the measured quantities (x-axis). Horizontal error bars were taken from the NIST test report [7]. Vertical error bars were computed using the results of the sensitivity study.

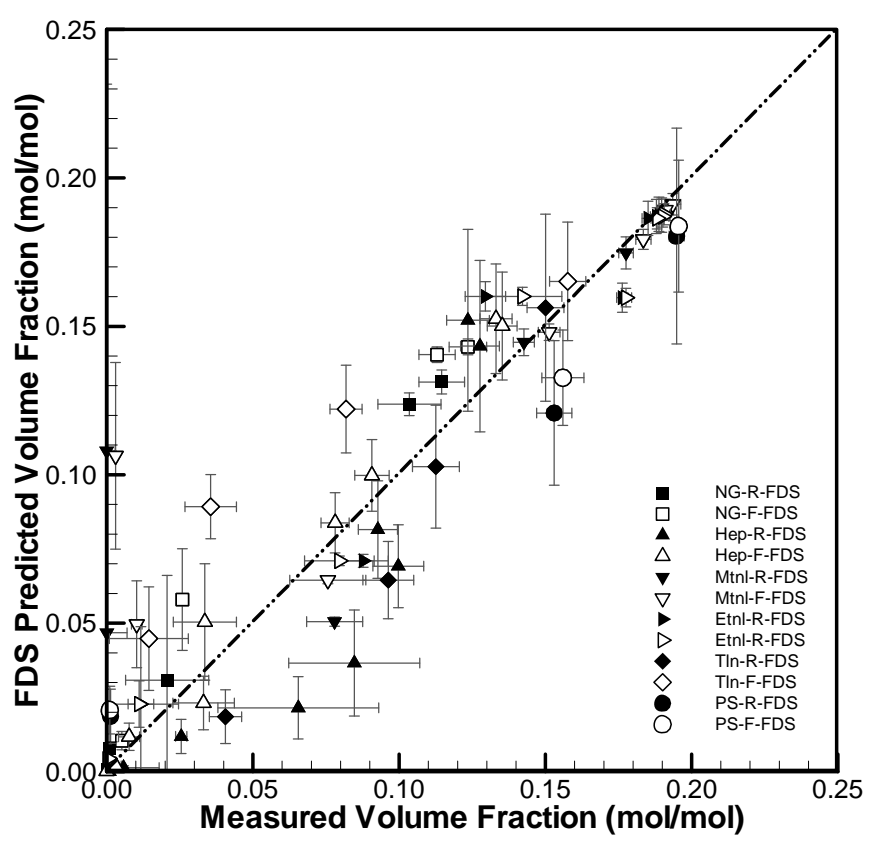

Fig. 2. FDS predicted vs. measured front and rear $\mathrm{O}_{2}$ volume fraction

Figure 2 shows the result for the two $\mathrm{O}_{2}$ measurement locations in the compartment. For $60 \%$ of the dataset the predictions and measurements agree within uncertainty. For the other points there is not a clear trend either over- or under-predicting the measurements. It is observed that predictions for the large methanol spray fire (near $0,0.1$ ), are particularly poor. A review of the simulation results indicates that the droplet evaporation algorithm was resulting in flow instabilities which resulted in the large $\mathrm{O}_{2}$ values. This is not surprising as these issues have been documented on the GoogleCode development site. 


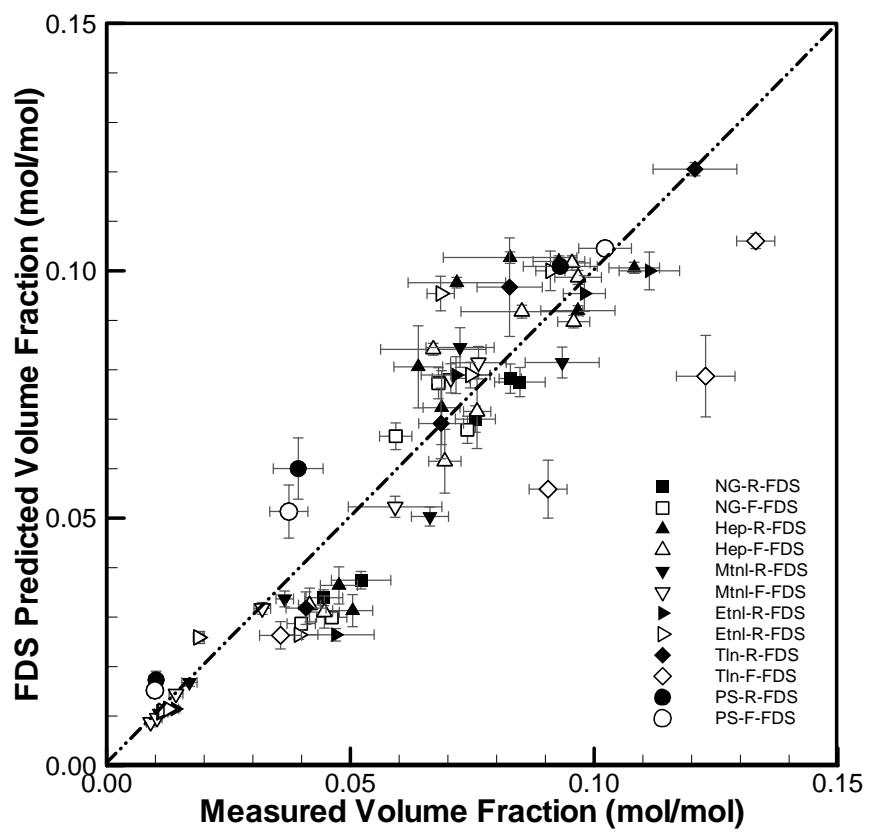

Fig. 3. FDS predicted vs. measured front and rear $\mathrm{CO}_{2}$ volume fraction

FDS predictions of the $\mathrm{CO}_{2}$ volume fraction, Fig. 3, were within the uncertainty for $36 \%$ of the dataset. With the exception of the rear location of the toluene data, those points that were not within the uncertainty were generally close to doing so, and if all sources of FDS uncertainty were accounted for then agreement would be likely. There is a trend towards under-prediction of the $\mathrm{CO}_{2}$ levels. This may result from the current combustion model which treats the reaction as two separate steps and as a result may create locations where $\mathrm{O}_{2}$ is fully consumed making $\mathrm{CO}$ when if parallel reactions were occurring some would be consumed by simultaneous oxidation of $\mathrm{CO}$. The root mean square of the relative difference between $\mathrm{CO}_{2}$ prediction and measurement was $19 \%$.

CO predictions, Fig. 4, were in agreement for $40 \%$ of the dataset. This is essentially the same performance as for $\mathrm{CO}_{2}$. The worst predictions are for the oxygenated fuels (methanol and ethanol). These fuels can form $\mathrm{CO}$ without the consumption of $\mathrm{O}_{2}$ from the air, which is a phenomena not accounted for in the current combustion model. Ignoring those data points, there is a trend towards over-prediction of CO. Given the $\mathrm{CO}_{2}$ performance, this is expected for the same reason as for the under-prediction of $\mathrm{CO}_{2}$.

Figure 5 shows the predicted vs. measured unburned fuel. $47 \%$ of the data points agree for this quantity. In general, for test conditions where unburned fuel were $>1.5 \%$, FDS is under-predicting the values. There are two likely contributors to this. The first is the sequential reaction steps. For a given quantity of oxygen, making only $\mathrm{CO}$ will consume more fuel than if $\mathrm{CO}_{2}$ is made. Secondly, FDS considers all unburned fuel to be the fuel molecule specified in the input file. Gas Chromatography of unburned fuel samples from the test indicates that the species present are primarily low molecular weight hydrocarbons. For the same mass of unburned fuel assuming it is the original fuel molecule would result in a lower volume fraction than if it were to exist as a number of smaller fuel molecules. This second contribution could be reduced by specifying a fuel molecule in the input file that maintains the stoichiometry but has a lower molecular weight. For example, $\mathrm{C}_{7} \mathrm{H}_{16}(100 \mathrm{~g} / \mathrm{mol})$ could be specified as $\mathrm{C}_{1.75} \mathrm{H}_{4}(25 \mathrm{~g} / \mathrm{mol})$ 


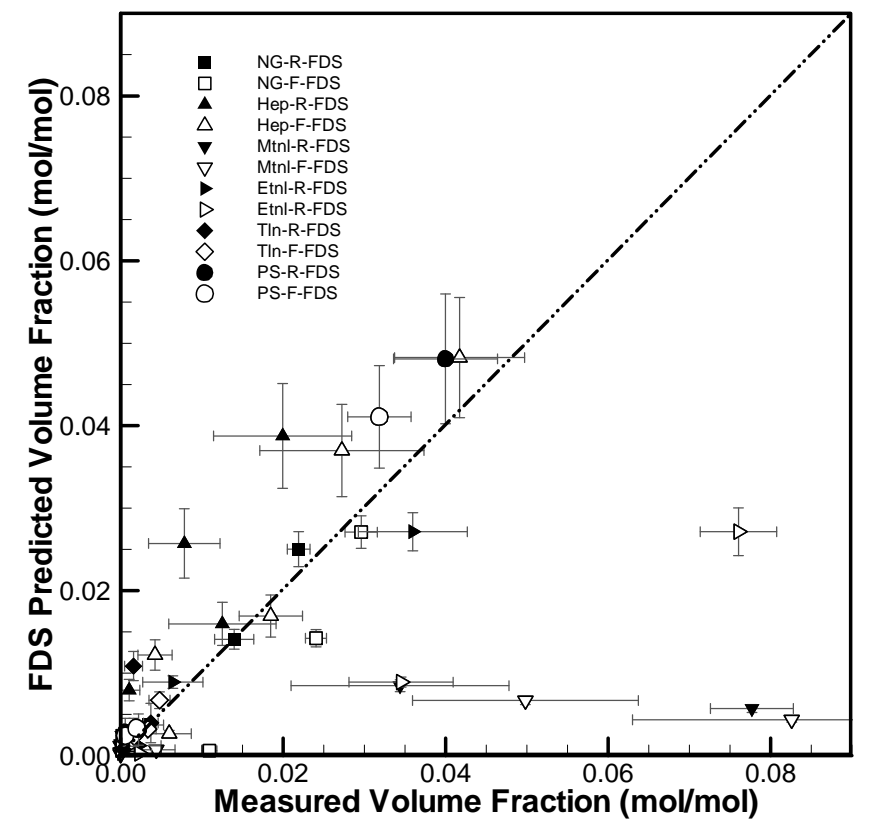

Fig. 4. FDS predicted vs. measured front and rear CO volume fraction

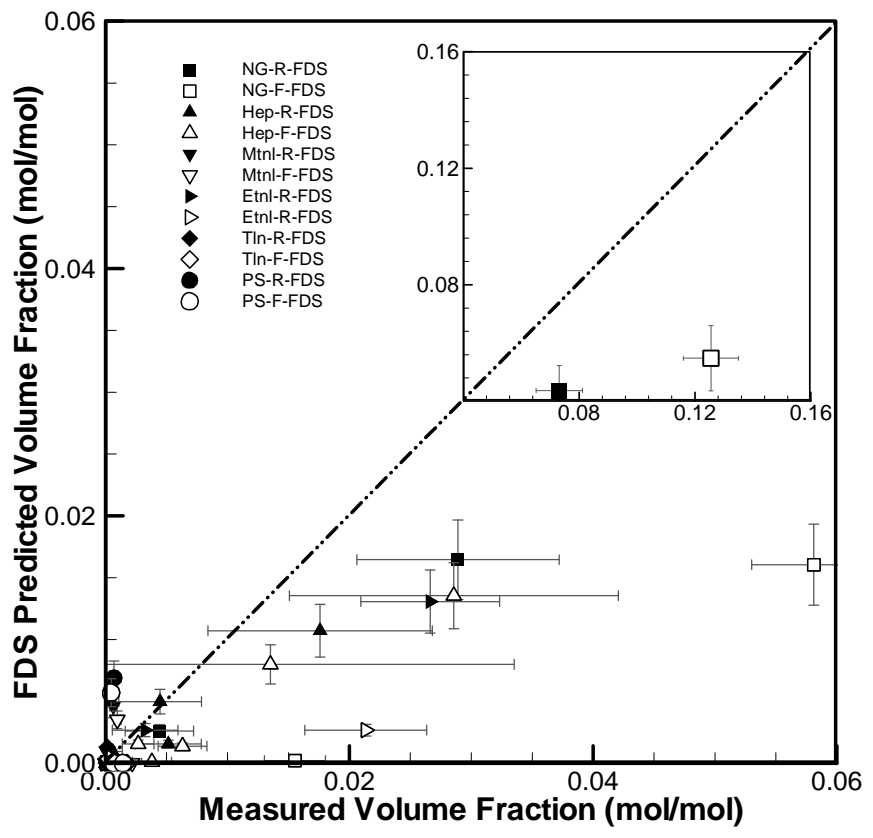

Fig. 5. FDS predicted vs. measured front and rear unburned fuel volume fraction

Figures 6 and 7 respectively show the quantities of upper and lower temperature which respectively agree within uncertainty for $28 \%$ and $17 \%$ of the data points. The rms relative difference for the upper measurements is only $10 \%$ with a maximum difference of $32 \%$ (for the previously discussed largest methanol spray fire). For the smaller fire sizes the upper temperature predictions are generally low compared to the data. This trend is not as evident for the larger fire sizes. For the lower points the rms relative difference is $18 \%$ with a maximum difference of $75 \%$ also for the methanol spray fire. Lower predictions are biased low in comparison to the measurements. 


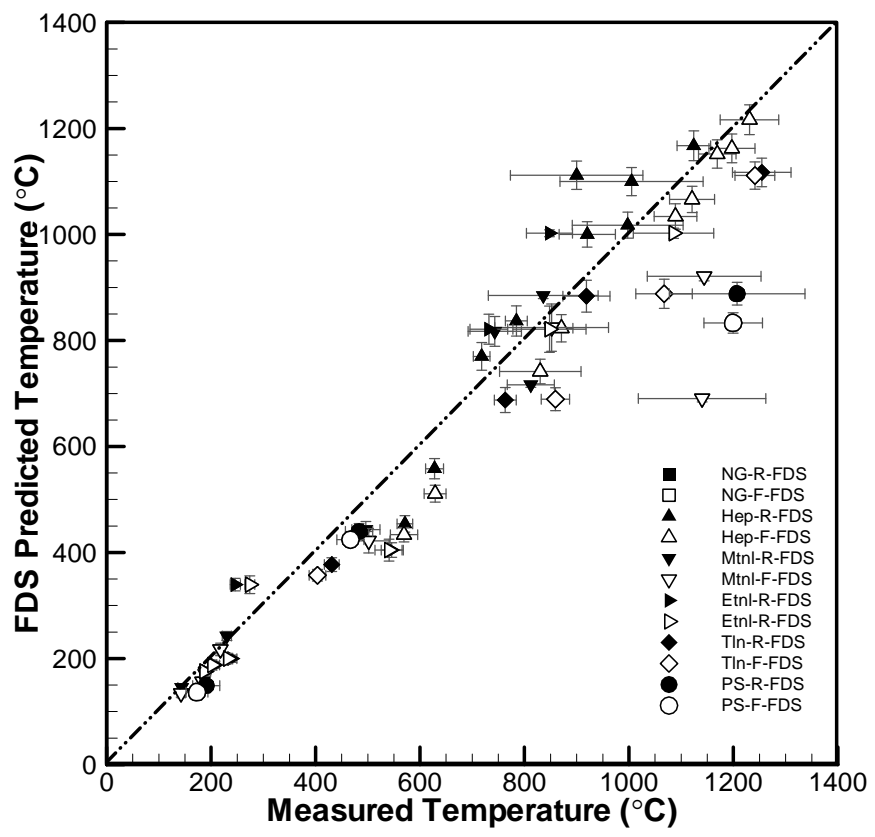

Fig. 6. FDS predicted vs. measured front and rear upper temperature

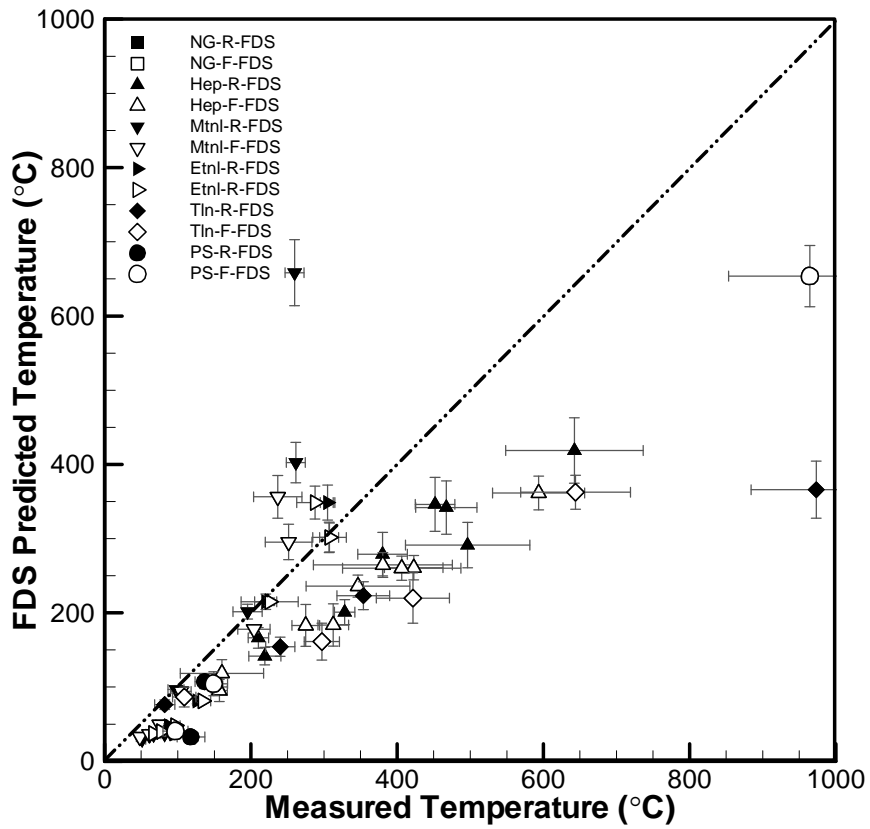

Fig. 7. FDS predicted vs. measured front and rear lower temperature

Figure 8 shows predictions vs. measurements for total heat flux to the floor. The predictions match the measurements for $44 \%$ of the data points. For the smaller fires the predictions are generally lower than the data. Since an FDS calculation does not generally resolve flame temperatures, FDS uses a fixed radiative fraction in grid cells with heat release. For well ventilated fires (lower upper layer temperatures and a less optically thick environment) this assumption dominates the radiation source term and is a likely contributor to the under prediction. For larger fire sizes there isn't a clear trend towards either over prediction or under prediction; however, the largest relative differences are occurring when FDS over predicts the heat flux. One possible reason for this is currently the radiation model does not distinguish where the heat release 
originates. The fixed radiative fraction assumption was originally developed to account for unresolved flames. In a hot upper layer with bulk oxidation of CO, this assumption is still being applied, but in this case the layer temperature should be accurate enough for generating a source term. This could be resulting in too large of a radiative source term in the upper layer. Overall the rms difference in the heat flux prediction was $41 \%$.

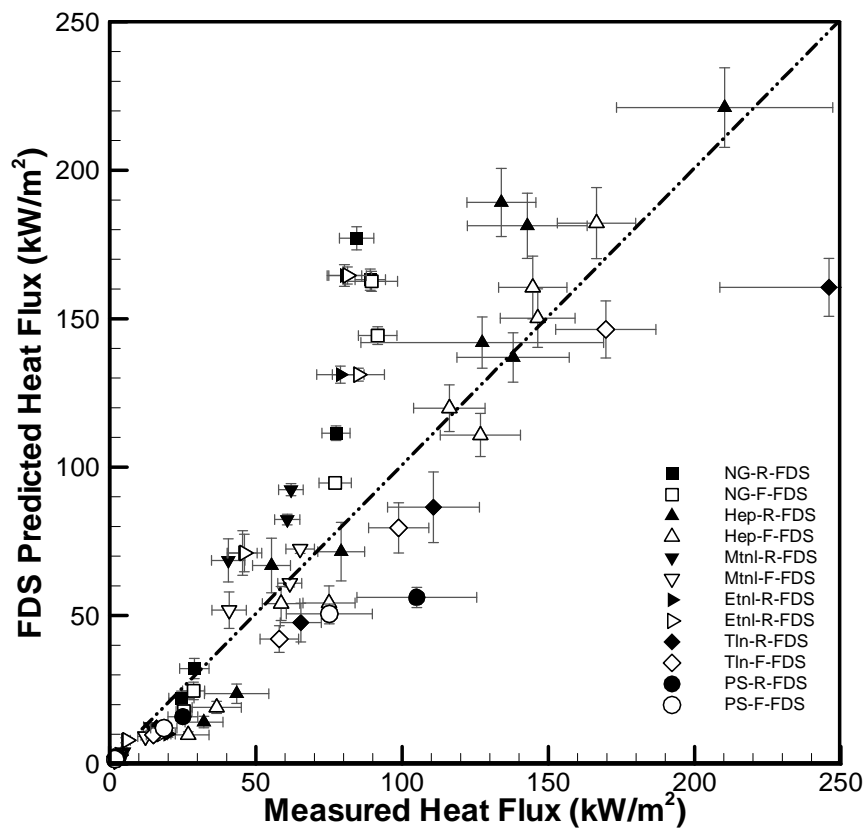

Fig. 8. FDS predicted vs. measured front and rear floor total heat flux

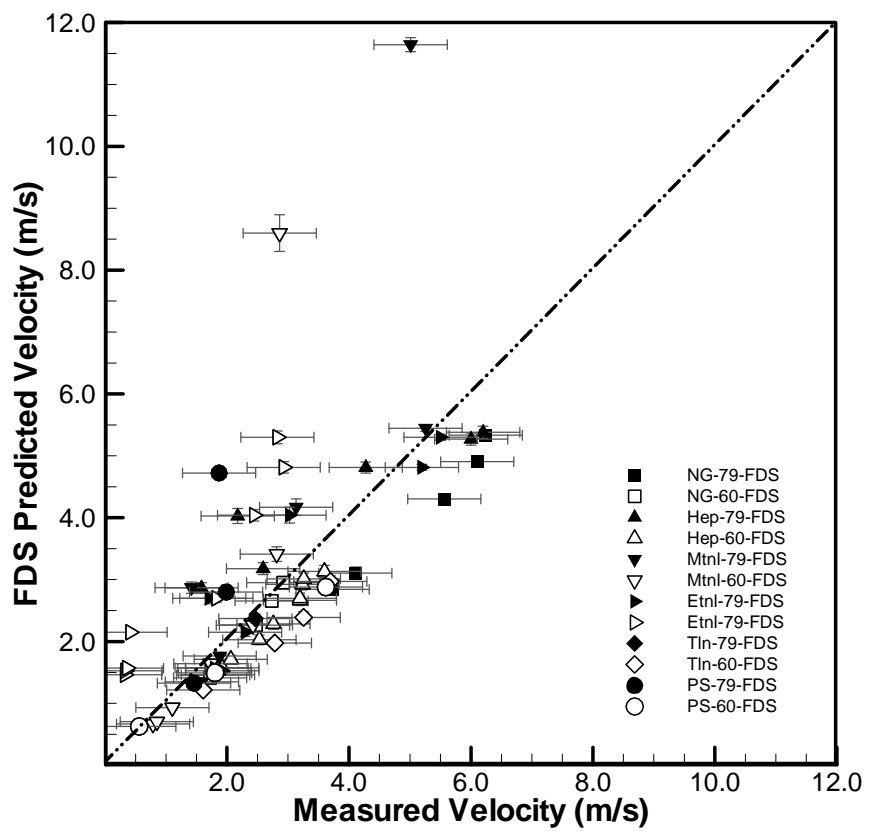

Fig. 9. FDS predicted vs. measured doorway centerline velocities at $0.79 \mathrm{~m}$ and $0.60 \mathrm{~m}$ 


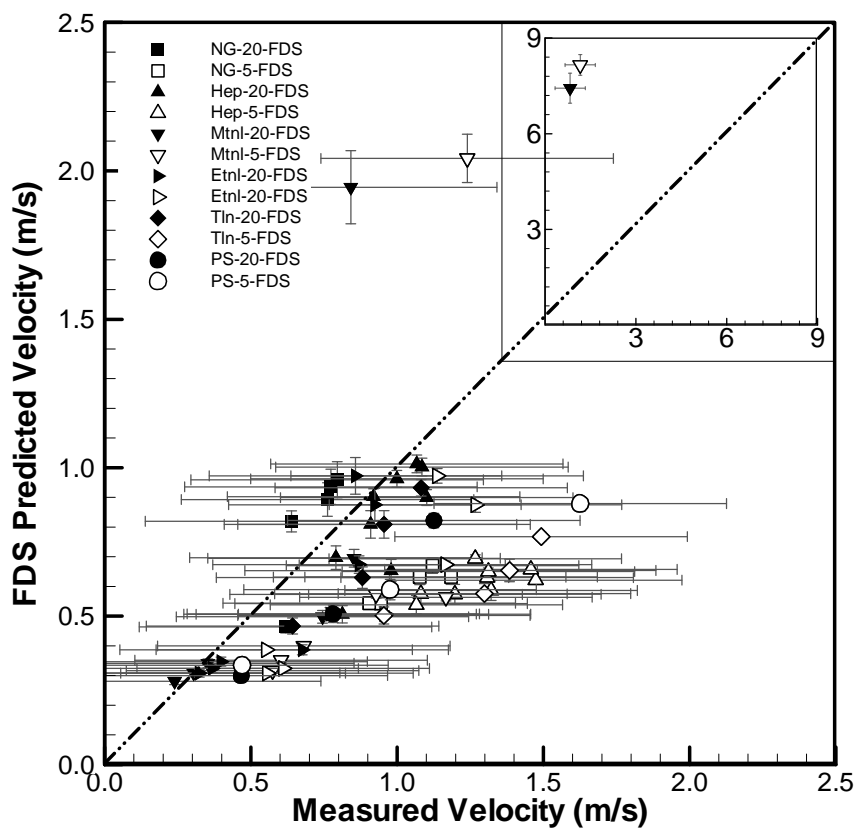

Fig. 10. FDS predicted vs. measured doorway centerline velocities at $0.20 \mathrm{~m}$ and $0.05 \mathrm{~m}$

Figures 9 and 10 show predicted vs. measured velocities in the upper and lower portion of the doorway to the compartment. FDS predicted within uncertainty $61 \%$ of the time in the upper doorway and $72 \%$ of the time in the lower doorway. It is noted that measurement uncertainties were fairly large for these quantities. As with other quantities the worst outliers resulted from the methanol spray fire. This is an indication that further development of the droplet routines is needed. In the lower door, FDS generally under predicted the measured values. In the upper doorway there were more data points where the FDS predictions were lower than the data; however, among data points where predictions lay outside the uncertainties there were more over predictions. After removing the methanol outliers, the rms differences were $44 \%$ for the upper locations and $31 \%$ for the lower locations. However, it is noted that the data uncertainty averaged $36 \%$ for the upper and $64 \%$ for the lower.

\section{CONCLUSIONS}

FDS v5 was used to simulate 11 of the 17 reduced scale enclosure tests documented in [7]. A sensitivity analysis was performed for two of the major contributors to the model input uncertainty. This analysis revealed the velocity predictions and upper layer temperature predictions were not particularly sensitive to the heat release and material property uncertainties. Most other quantities had uncertainties ranging up to $15 \%$. The exception was gas concentrations when the predicted value was low $(<<1 \%)$ in which case uncertainties were large (> $100 \%$ ); however, in these cases the relative difference was low.

With the exception of the alcohol tests FDS correctly predicted the trends in various gas species and matched the measurements within uncertainty for approximately half the data set. It can be seen that the current implementation of the two-step combustion model is over predicting $\mathrm{CO}$, under predicting $\mathrm{CO}_{2}$, and under predicting unburned fuel. The assumption that the first step is infinitely fast combined with performing the two steps sequentially rather than allowing for some simultaneous reaction is a likely contributor to this.

With the exception of the largest fire size of the methanol spray fires, velocities were well predicted by FDS. However, the measured data for velocity (especially in the lower layer) has fairly large uncertainties. Relative differences between FDS predictions and the measurements were on the order of the measurement uncertainty.

Temperature predictions by FDS did not match the data within uncertainty as well as other parameters. However, in the upper layer while only $28 \%$ of the predictions were within uncertainty the average relative 
difference was only $10 \%$. In terms of predicted heat flux, the relative differences in temperature prediction did not translate to the heat flux as FDS predictions vs. measurements matched within uncertainty for over $40 \%$ of the dataset. The pattern of relative differences in the heat flux predictions suggest that the radiative source term for layers with oxidizing CO may need to be revisited.

The new two step combustion model has been shown capable of reproducing the conditions within the reduced scale enclosure over a range of fuels and fire sizes. While, additional work in the underlying mechanics of implementing the model is required, the overall approach (which adds little in terms of a computational burden) is a success.

\section{ACKNOWLEDGEMENTS}

This work was funded by the United States Department of Commerce, National Institute of Standards and Technology, Building and Fire Research Laboratory through the Fire Grants Program.

\section{REFERENCES}

[1] Salley, M., "Verification \& Validation of Selected Fire Models for Nuclear Power Plant Applications,” US Nuclear Regulatory Commission Report NUREG-1824, 2007.

[2] Pope, N.D., Bailey, C.G., (2006) Quantitative Comparison of FDS and Parametric Fire Curves with Post-Flashover Compartment Fire Test Data, Fire Safety Journal 41: 99-110. http://dx.doi.org/10.1016/j.firesaf.2005.11.002

[3] Floyd, J.E. and McGrattan, K.B., "Multiple Parameter Mixture Fraction With Two-Step Combustion Chemistry for Large Eddy Simulation”, Proceedings of Interflam 2007, 2007, pp 907918.

[4] McGrattan, K ., Hostikka, S., Floyd, J., Baum, H., and Rehm, R., "Fire Dynamics Simulator (Version 5): Technical Reference Guide”, National Institute of Standards and Technology Report NIST SP 1018-5, Gaithersburg, MD, 2007.3

[5] Fox, R. Computational Models for Turbulent Reacting Flows, Cambridge University Press, Cambridge UK, 2003.

[6] Westbrook, C. and Dryer, F. (1981), Simplified Reaction Mechanisms for the Oxidation of Hydrocarbon Fuels in Flames, Combustion Science and Technology 27:31-43. http://dx.doi.org/10.1080/00102208108946970

[7] Bundy, M., et al., "Measurments of Heat and Combustion Products in Reduced-Scale VentilationLimited Compartment Fires,” National Institute of Standards and Technology Report NIST TN 1483, Gaithersburg, MD, 2007. 